\title{
Brenta, Noemí (2019). Historia de la deuda externa Argentina. Buenos Aires: Capital Intelectual, 240 p.
}

\author{
Ignacio Rossi \\ ignacio.a.rossi@gmail.com \\ Universidad Nacional de Luján, Universidad Nacional \\ de General Sarmiento, Argentina
}

Recepción: 17 Noviembre 2019

Aprobación: 16 Julio 2020

Publicación: 13 Noviembre 2020

Cita sugerida: Rossi, I. (2020). [Revisión del libro

Historia de la deuda externa Argentina por N. Brenta].

Anuario del Instituto de Historia Argentina, 20(2), e129.

https://doi.org/10.24215/2314257Xe129

Este libro se ocupa de un tema de suma urgencia para los argentinos: la deuda externa. Con un estilo literario apto para todo público, pero sin perder la rigurosidad analítica de los procesos históricos, Noemí Brenta periodiza la historia de la deuda externa desde la dictadura iniciada en 1976 hasta la actualidad. El libro se estructura en seis capítulos en los que se respeta la diacronía de la deuda, a la vez que se propone una periodización configurada en función de los problemas y coyunturas políticas más relevantes de cada etapa.

El capítulo uno tiene el objetivo principal de conceptualizar la deuda externa en moneda extranjera y analizar los principales indicadores que la convierten en un problema económico y social. Como sostiene la autora, el tema cobra relevancia porque la deuda actualmente se encuentra en una "zona roja”. En esta clave, la creación de deuda fuera de las jurisdicciones nacionales, los principales organismos que se encargan de medirla, cuándo y cómo advertir una situación de insolvencia y/o iliquidez fiscal y su relación con la austeridad, son parte de los temas analizados. De una forma didáctica que le escapa al tecnicismo económico, el capítulo funciona como una introducción conceptual al libro. 
El capítulo dos analiza el problema de la deuda durante el gobierno dictatorial (1976-1983). La principal controversia que se examina es el misterio que constituye la medición exacta de la deuda en aquellos años, su discrepancia y contradicciones entre los organismos encargados de calcularla. En primer lugar se aborda, desde el plan económico del Ministro de Economía Martínez de Hoz, la apertura a un inusitado endeudamiento a través del financiamiento del FMI y los bancos comerciales. También aborda el desarrollo de "la bicicleta financiera" que, a través de la denominada "tablita cambiaria" -política económica que establecía devaluaciones preanunciadas por debajo de la inflación-, contribuyó a un mayor endeudamiento en aquellos años. Luego, analiza la crisis bancaria desarrollada desde 1980 como causa de las elevadas tasas de interés, la desregulación del sistema financiero y la inmovilidad del gobierno ante las señales de peligro. El capítulo finaliza con el escandaloso proceso de estatización de la deuda externa mediante los seguros de cambio que el Banco Central proveía a los privados e indaga quiénes fueron los principales acreedores, deudores y a dónde se dirigieron los fondos de la deuda externa.

El capítulo tres aborda el problema de la deuda durante dos momentos del gobierno de Alfonsín: el tibio intento de distinguir la legitimidad e ilegitimidad de la deuda contraída por el gobierno militar y el "giro realista" llevado a cabo desde 1984. En el primer período, las disputas que se generaron entre Argentina y EE.UU. por considerar la deuda como un problema político o financiero, respectivamente, llevaron a que se creara la Comisión Investigadora de Ilícitos Económicos en el Senado y a que, de la mano del canciller Dante Caputo, la Argentina, Brasil y México, -los países más endeudados-, le imprimieran un carácter político al asunto en el Consenso de Cartagena de Indias. Sin embargo, la corporización de los bancos estadounidenses, que contemplaban el mayor volumen de la deuda, inclinó el tablero a su favor mediante la estrategia de negociar caso por caso. El segundo período se caracteriza por la llegada de un nuevo equipo económico con Juan Sourrouile y el lanzamiento del Plan Austral. La autora analiza las políticas económicas en relación a la aceptación del problema de la deuda externa en los términos que los acreedores y organismos internacionales lo imponían. Las nuevas líneas de crédito acordadas y los regímenes de capitalización de deuda se combinaron con los intentos de reforma del Estado en el marco del Plan Baker y los endebles desembolsos que otorgaban el BM y el BID. El capítulo finaliza con la disputa entre el BM y el FMI por aplicar reformas estructurales, la falta de financiamiento y acuerdos con EE.UU., la moratoria de hecho declarada en abril de 1988 y su conjugación con los levantamientos militares, la fuga de capitales, la recesión y una hiperinflación de 3.079 $\%$ en 1989.

El capítulo cuatro, se ocupa del periodo 1989-2001 en tres partes. En la primera, se aborda el marco del Plan Brady y las reformas que permitieron las privatizaciones de los activos públicos en un contexto de avance del neoliberalismo. La segunda hiperinflación en diciembre de 1989 dio cabida al Plan del Ministro de Economía Erman González caracterizado por una apertura comercial y financiera ideada según el Consenso de Washington. La autora analiza aquí cómo, a través de un superávit comercial originado en una fuerte recesión y un tipo de cambio alto, junto a la venta de activos públicos, se redujo la deuda externa. En segundo lugar, se examina en detalle el Plan Brady, mediante el cual se convirtió deuda en bonos canjeables por activos públicos, y la instrumentación del mismo por el FMI. Brenta sostiene que, en este periodo la colocación de bonos se convirtió en el principal instrumento de la deuda del sector público, en donde capitales nacionales y extranjeros compraron títulos al Estado que excedían las tasas de interés internacionales. La tercera etapa comienza con el gobierno de la Alianza, el cual significó una continuidad en términos de políticas económicas. La autora desmitifica el problema del déficit público, describe los problemas de insolvencia que asolaban a la Argentina en el 2000 y examina el blindaje organizado por el FMI como estrategia conjunta de financiamiento para evitar una moratoria. Este capítulo finaliza con la figura de Domingo Cavallo y los "superpoderes" que se le otorgaron en el Ministerio de Economía, período en el que se caracterizó por mayor austeridad, caída de las reservas del Banco Central, fuga de capitales y, finalmente, el default y la crisis económica más grande de la historia en el 2001. 
El favorable contexto internacional, el alza del PBI nacional y la reducción de deuda pública son los ejes del capítulo cinco. El paulatino traspaso de deuda en manos privadas a entes interestatales constituyó una estrategia que permitió reducir la injerencia de los acreedores internacionales y lograr mejores condiciones de pago. Noemi Brenta enfatiza en los canjes de 2005 y 2010, liderados por las figuras de Nestor Kirchner y el Ministro de Economía Roberto Lavagna. La autora focaliza en el acuerdo por el cual el Estado retiró 62,3 mil millones de dólares de deuda en default a cambio de títulos nuevos por 35,3 mil millones, un adicional ligado al crecimiento del PBI y la reducción de deuda en moneda extranjera. La reapertura del canje en 2010 puso en peligro el pago de la deuda logrado entre 2006-2007 sobre la plataforma de una crisis originada en el comercio exterior. Como señala la autora, la caída de las exportaciones y del PBI en un contexto internacional cambiante desde el 2008 exigió normalizar la deuda en default. Este segundo canje puso en el centro de la escena a los llamados "fondos buitre" que, encargados de comprar deuda en cesación de pagos a precios reducidos y exigir cobrarla con plenos intereses acumulados, se acogieron bajo la figura del juez Thomas Griesa. La confluencia de los intereses del gobierno estadounidense, agentes financieros e interesados en el negocio de las emisiones, operó en favor de Argentina que, a su vez, se refugiaba en el paraguas de la ONU.

El último capítulo analiza una nueva etapa de endeudamiento durante el gobierno de Mauricio Macri. Durante el 2016 el crecimiento de la deuda es dirigido a eliminar el control cambiario y pagar a los fondos buitre. El endeudamiento preanunciado del gobierno que se destinaría a inversiones en infraestructuras, además de ser ínfimo en relación a la economía argentina, no se concretó. Noemí Brenta inserta la lógica de endeudamiento en relación a los alicientes norteamericanos para integrarse a las cadenas de producción mundiales en oposición al proyecto de la seda chino. En este sentido, el levantamiento de las restricciones para las operaciones financieras en moneda extranjera y las prestas negociaciones para efectuar los pagos a los fondos buitre se dirigieron a favorecer a los sectores financieros y a lograr una apertura al crédito internacional que nunca llegaría. Durante los primeros meses de 2018, al desfavorable contexto internacional y nacional se sumó la profundización del ajuste y la colocación de deuda por 9 mil millones de dólares en bonos. El regreso a los préstamos del FMI fundado en las turbulencias internacionales y el desmantelamiento de los mecanismos de protecciones externos de la economía argentina son duramente criticados por la autora. El capítulo finaliza con la paradoja del aumento del endeudamiento a través de la emisión de letras y un nuevo acuerdo stand by con el FMI.

Noemí Brenta concluye que la deuda externa debe preocuparnos. Por un lado, rescata que la sociedad actualmente es más consciente del problema a causa de una asidua memoria colectiva. Pero, por otro lado, advierte que los bienes del país, como los bancos estatales, la moneda nacional, los recursos naturales, etc., deben ser protegidos de la constante puja con los acreedores externos. Asimismo, subraya el problema que constituye, frente a las fluctuaciones de los precios internacionales, una economía basada en la exportación de materias primas como principal rubro generador de divisas. Sin ninguna duda, este libro es imprescindible en los tiempos actuales, porque conocer la historia y los efectos que en el pasado reciente han generado los diversos mecanismos de endeudamiento, hoy constituye una necesidad para pensar la soberanía nacional, la distribución de la riqueza y las políticas económicas en un nuevo contexto de endeudamiento que se abrió en el año 2016. 